also take into account the public perspective, which includes economic and social spheres.

The economic review covers issues of economic efficiency, namely direct effects, indirect and external effects. The social sphere solves the problem of equity, which includes the distribution of costs and benefits over time and between groups and locations. The task of the scheduler is to determine the optimal power indicator. Its purpose is the financial and economic viability of the relevant investment project.

Port capacity, which is defined here as the maximum capacity of a seaport to carry cargo, is a combined product of port capacity and related services. Port capacity planning is complicated by the presence of issues: port-commercial and public interests, competition, economies of scale, capacity and technological development. Physically expanding the port's capacity is an interesting strategy because it improves the quality of service, making the port more attractive to freight carriers, and it allows for an autonomous increase in port demand.

УДК 331.45

DOI: $10.35340 / 2308-104 X .2021 .91-2-11$

\section{ОПТИМІЗАЦІЯ ОХОРОНИ ПРАЦІ ФАХІВЦІВ ІТ-ГАЛУЗІ}

\author{
КАЛЬЯНОВ А. В., \\ доктор медичних наук, старший \\ науковий співробітник, професор \\ кафедри охорони праці й \\ навколишнього середовища \\ ДВНЗ «Приазовський державний \\ технічний університет»
}

\section{OPTIMIZATION OF OCCUPATIONAL SAFETY OF THE IT INDUSTRY SPECIALISTS}

\author{
KALYANOV A., \\ Doctor of Medical Science, Senior \\ Research Officer, Professor of the \\ Department of Labour and \\ Environmental Protection, \\ SHEl «Priazovsky State Technical \\ University»
}

Визначено проблеми та основні причини щодо відсутності належного забезпечення охорони праці в IT-галузі, окреслено негативи використання інформаційних технологій, проведена експертна оцінка впливу окремих складових на розвиток інформаційної культури ITфахівців. Запропоновано заходи щодо вдосконалення охорони праці при впровадженні нових технологій IT-галузі.

Ключові слова: охорона праці, IT-галузь, інформаційна культура, нові інформаційні технології.

Определены проблемы и основные причины отсутствия надлежащего обеспечения охраны труда в IT-отрасли, негативы использования информационных технологий, проведена экспертная оценка влияния отдельных составляющих на развитие информационной культуры IT-специалистов. Предложены меры по оптимизации охраны труда при внедрении новых технологий в IT-отрасли.

Ключевые слова: охрана труда, IT-отрасль, информационная культура, новые информационные технологии.

The problems and main reasons for the lack of adequate provision of labour protection in the IT-industry, the negative aspects of the use of information technology were determined, an expert assessment of the impact of individual components on the development of information culture 
of IT-specialists was carried out. Measures to optimize labour protection in the introduction of new technologies in the IT-industry were proposed.

Key words: labour protection, IT industry, information culture, new information technologies.

Постановка проблеми. В сучасний період найбільш актуальним завданням $€$ цифровізація економки знань, масового переводу використовуваних технологій на цифрову основу. Цифрова економіка сприяе за допомогою спеціальних методів підвищенню ефективності роботи як окремих підприємств, так і цілих галузей економіки. Цифровізація виробництва може забезпечити економію у 2025 році понад 3 трлн дол. [1]. За економічними оцінками використання нових технологій в IT-галузі може забезпечити повернення інвестицій максимум за один рік [2].

Сучасний досвід запровадження новітніх інформаційних технологій (НIT) в Україні свідчить про певні потреби у фахівцях цієї галузі в різних секторах економіки.

Потреба у фахівцях комп'ютерної галузі щорічно зростає. Так, за нашими розрахунками, для вирішення завдань у рамках складних систем, у т.ч. у системній інженерії, на 10 тис. працездатного населення, а також забезпечення роботи в режимі високої невизначеності і швидкої зміни щодо прийняття управлінських рішень, реагування на зміни умов праці, розподілу наявних ресурсів і управління власним часом потрібно 17 компетентних і досвідчених адміністраторів, програмістів, операторів та інших категорій фахівців IT-галузі. Цей показник в рамках Донецького регіону збільшився у 8 разів, Україні - в 11 разів.

Професії фахівців IT-галузі за своєю привабливістю за оцінками випускників загальноосвітніх закладів входять до престижних ТОПпрофесій, займаючи четверте рангове місце. Середня заробітна плата працівників у галузі новітніх інформаційних технологій в Україні перевищує 100 тис. грн на місяць, а за кордоном (європейські країни понад 4000 \$). Саме цей факт обумовлює міграційний потік і відтік кадрів за межі України. Останнім часом з'явилася нова професія системний інтегратор - фахівець зі створення розумного дому.

Відповідно до 13 статті Закону України «Про охорону праці» роботодавець зобов'язаний створити на робочому місці в кожному структурному підрозділі умови праці відповідно до вимог нормативноправових актів, а також забезпечити додержання основних положень законодавства України [3].

Аналіз умов праці фахівців IT-галузі свідчить, що при роботі 3 комп'ютерною технікою на їх організм можливий вплив таких шкідливих чинників, як мікроклімат на робочому місці (температура повітря, його швидкість, відносна вологість, барометричний тиск, тепловиділення), шум у приміщенні, який перевищує гранично допустимі рівні для програмістів та операторів (50-65 Д6А), неіонізуючі випромінювання, високий рівень іонізації повітря (позитивні іони - понад 2300, негативні >4000), статичні характеристики електричного струму. Важливу роль у забезпеченні санітарно-гігієнічних умов праці відіграють психофізіологічні фактори операторів та програмістів (мислення, швидкість і точність реакцій,

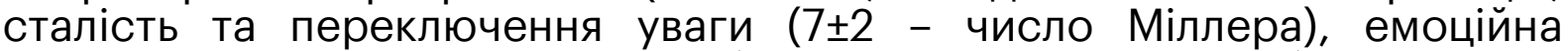
стійкість, координація рухів, особистісний показник - недбалість щодо виконання вимог охорони праці, стресостійкість та інші). Нерідко 
робота за комп'ютерною технікою протікає в умовах недостатньої природної освітлюваності (коефіцієнт природної освітленості менше 2,0) та загального штучного освітлення - менше 350 люкс). Використання штучних джерел світла характеризується впливом таких світлотехнічних факторів як надмірна яскравість, мерехтіння зображення та джерела світла, недостатня контрастність, сумерковий ефект люмінесцентних ламп тощо.

При оцінці умов праці фахівців IT-галузі необхідно визначати так званий інтегральний узагальнюючий коефіцієнт (Куп) [4].

$$
\text { Куп }=a_{1} \cdot a_{2} \ldots a_{n}
$$

де $a_{1}, a_{2}, a_{n}$ - індекси відхилення фактичних умов ( $\left.{ }_{y}\right)$ праці від нормативних значень $\left(\mathrm{Y}_{\mathrm{H}}\right)$.

Вони визначаються за формулою:

$$
\mathrm{a}=\frac{\mathrm{y}_{\phi}}{\mathrm{y}_{\mathrm{n}}}
$$

Чим ближчими є значення Куп до 1, тим більше умови праці відповідають нормативним вимогам.

Тривала робота за комп'ютером (понад 50\% робочого часу) призводить до психофізіологічного перенавантаження організму, стомлення зорового аналізатора i як наслідок - погіршення психосоматичного здоров'я фахівців IT-галузі у вигляді загальної захворюваності та захворюваності 3 тимчасовою втратою працездатності, що призводить до суттєвих економічних збитків.

При недотриманні умов праці та індивідуальних режимів праці і відпочинку мають місце тривале статичне навантаження та порушення кровопостачання головного мозку. Тому можливі наступні симптоми та прояви у вигляді зміни артеріального тиску, запаморочення, оніміння, болі в руках, порушення сну, зниження розумової працездатності.

Для оптимізації умов праці фахівців ІТ-галузі необхідно використовувати всі переваги системи управління охороною праці (СУОП) шляхом інтеграції правової, організаційної та управлінської складової на засадах інформаційного менеджменту та інтегрованих систем менеджменту, включаючи систему Кайдзен.

Аналіз останніх досліджень і публікацій. Розвиток НІТ докорінно змінює всі сфери сучасного життя, у т.ч. підвищує розвиток економіки. Це потребує подальшого збільшення інвестицій в IT-галузь, розробку стратегічних програм наукових досліджень, формування відповідного рівня інформаційної культури фахівців. У сучасний період відбувається перехід на більш досконалі НІТ з високою економічною ефективністю, використання розумних видів виробництв $[5,6,7]$. Такий підхід дозволить покращити умови праці, майже у 2 рази знизити ризик розвитку загальних і професійних захворювань. Для цього потрібне системне використання заходів 3 діджиталізації в охороні праці фахівців IT-галузі.

Останнім часом питанням охорони праці фахівців ІТ-галузі приділяється певна увага. Проте сьогодення оптимізація охорони праці в сфері комп'ютерних технологій $€$ дуже важливою і нагальною, яка потребує додаткового і поглибленого дослідження. У цьому зв'язку уявляється актуальним і доцільним розробка напрацювань з оптимізації охорони праці в IT-галузі. 
Метою статі є розробка заходів з оптимізації охорони праці фахівців ІТ-галузі.

Виклад основного матеріалу дослідження. Провідною складовою СУОП є інформаційна культура (IK) фахівців IT-галузі. Здійснена нами експертна оцінка в рамках 15 складових людського потенціалу (ЛП) дозволила визначити роль та місце рівня інформаційної культури (табл. 1)

Таблиця 1

Рангова оцінка компонентів інформаційного потенціалу [8, с. 71]

\begin{tabular}{|l|l|}
\hline \multicolumn{1}{|c|}{ Компоненти потенціалу } & \multicolumn{1}{|c|}{ Х \pm Sх. ранги } \\
\hline Рівень інформаційної культури & $2.08 \pm 0.20$ \\
\hline Навички щодо аналізу та системної обробки інформації & $2.23 \pm 0.25$ \\
\hline Інформаційні потреби & $2.54 \pm 0.25$ \\
\hline Володіння сучасною комп'ютерною технікою & $3.15 \pm 0.16$ \\
\hline
\end{tabular}

Саме рівень IK можна розглядати як провідну детермінанту сучасного соціуму, важливий чинник результативності процесів інформатизації в галузі економіки і соціальної сфери України [8]. Наявний рівень IK фахівців IT-галузі сприяє інтегруванню складових НІT (правова, економічна, соціологічна, технологічна, психологічна, ергономічна підсистеми), мотивації та свідомому ставленню людини до виконання вимог законодавства України в сфері охорони праці. Ії також можна розглядати як підґрунтя для обґрунтованого вибору потрібних стратегій охорони праці (фінансові, інвестиційні, диверсифікаційні, інноваційні, технологічні).

В різних структурних підрозділах підприємств і організацій окремих галузей економіки наявний рівень IK різний. Тому для ії підвищення потрібний диференційований підхід щодо використання сучасних форм і методів підготовки фахівців інформаційної сфери. Встановлено, що найбільш вагомими факторами формування та розвитку IK $€$ освіта (16,6\%), рівень інтелекту $(14,2 \%)$, вік людини (11,9\%), духовність (11,9\%), комунікабельність $(11,9 \%)$ [8]. IK - це провідна характеристика нового покоління фахівців інформаційного суспільства, яка сприятиме використанню валідної соціальноекономічної інформації в рамках СУОП.

Заходи з оптимізації охорони праці фахівців IT-галузі можна поділити на наступні модулі: правові, економічні, організаційні, санітарно-гігієнічні, психофізіологічні, медико-біологічні.

Для належного правового забезпечення охорони праці потрібно обґрунтувати та включити у державний класифікатор професій ДК-0032010 нові професії комп'ютерної галузі, а до тарифно-кваліфікаційного довідника - основні види робіт, розряди стосовно цих професій та посад, переглянути та затвердити відповідні нормативно-правові акти (стандарти підприємств) для регламентації охорони і безпеки праці 3 врахуванням НIT.

Серед економічних заходів потрібно переглянути розміри посадових окладів фахівців нових професій, зайнятих на нових поколіннях комп'ютерної техніки 3 врахуванням нервово-психічної напруженості праці, передбачити у колективних договорах підприємств та організацій відповідні пільги та компенсації за результатами атестації умов позикової праці (аутстафінг, аутсорсинг).

Важлива роль належить організаційним факторам (розробка гнучких графіків роботи, використання дистанційної роботи, структурування перерв операторів (програмістів) залежно від категорії 
та групи робіт (читання інформації, діалоговий режим, введення інформації, творча робота (налагодження програм) тощо [4].

Санітарно-гігієнічні заходи потрібні для здійснення моніторингу умов праці фахівців IT-галузі, планування та фінансування подальшої їх оптимізації в рамках СУОП і можливостей колективного договору щодо доведення показників умов праці та факторів трудового процесу до гігієнічних нормативів (гранично допустимі рівні, гранично допустимі концентрації, допустимі рівні трудового процесу відповідно до Гігієнічної класифікації праці).

Використання нових поколінь комп'ютерної техніки потребує оцінки професійної придатності працівників на засадах здійснення психофізіологічної експертизи (відповідно до професії, віку, статі та розряду зорової роботи).

Серед медико-біологічних заходів необхідне проведення попередніх та періодичних медичних оглядів фахівців IT-галузі (цільові та поглиблені на предмет оцінки стану психосоматичного здоров'я), використання системних заходів 3 медичної, психологічної та професійно-трудової реабілітації їх здоров'я та розумової працездатності.

Висновки i перспективи подальших досліджень. Системна реалізація заходів 3 оптимізації охорони праці фахівців ІТ-галузі сприятиме підвищенню соціально-економічної їх ефективності. Перспективи подальших наукових досліджень полягають в інтегрованому поглибленому вивченні та прагматичному втіленні різноманітних заходів за правовими, економічними, організаційними, санітарно-гігієнічними, психофізіологічними, медико-біологічними модулями, які враховують нові покоління комп'ютерної техніки.

\section{Література:}

1. Мунгалов Д. Н., Капустян А. Е. Цифровизация экономики знаний. URL: http://sk.ru/news/b/artides/archive/2018/04/20/cifrovizac ija-ekonomiki-znaniy.asp.

2. Кокурина В. Развитие цифровых технологий в области охраны труда. URL: https://www.aetalon.ru/single - post/2018/02/22/.

3. Про охорону праці: Закон України (у редакції Закону від 21.11.2002. № 229-IV). Відомості Верховної Ради України. 2003. № 2 Ст.13.

4. Кальянов А. В. Методичні вказівки до розробки розділу «Охорона праці» у дипломних проектах для студентів факультету інформаційних технологій. Маріуполь: ДВНЗ «ПДТУ», 2019. 10 с.

5. Шконда В.В., Кальянов А. В. Культорологічні засади професійно-особистісного становлення майбутніх фахівців: монографія. Донецьк, 2012. 262 с.

6. Куприяновский В. П., Синягов С. А., Липатов С. И. и др. Цифровая экономика - умный способ работы. International Journal of Open Information Technologies. 2016. Vol. 4, No. 2. P. 231-238.

7. Кальянов А. В., Хлєстова О. А. Цифрова економіка в охороні праці. Наукові праці МАУП. Серія «Економічні науки». Вип. 2. (58). C. 16-21. URL: https://doi.org/10.32689/2523-4536-2019-02/58-16-21. 2019.

8. Шконда В. В., Кальянов А. В. Проблеми розвитку людського потенціалу на сучасному етапі: монографія. Донецьк: Донбас, 2012. 211 c. 
References:

1. Mungalov D. N., Kapustyan A. E. Tsifrovizatsiya ekonomiki znaniy. URL:http://sk.ru/news/b/artides/archive/2018/04/20/cifrovizacij a-ekonomiki-znaniy.asp.

2. Kokurina V. Razvitie tsifrovykh tekhnologiy $v$ oblasti okhrany truda. URL: https://www.aetalon.ru/single - post/2018/02/22/.

3. Pro okhoronu praci: Zakon Ukrajiny (u redakciji Zakonu vid 21.11.2002. \# 229-IV). Vidomosti Verkhovnoji Rady Ukrajiny. 2003. \# 2 St.13.

4. Kaljjanov A. V. Metodychni vkazivky do rozrobky rozdilu "Okhorona praci» u dyplomnykh proektakh dlja studentiv fakuljtetu informacijnykh tekhnologhij. Mariupolj: DVNZ «PDTU», $2019.10 \mathrm{~s}$.

5. Shkonda V. V., Kaljjanov A. V. Kuljtorologhichni zasady profesijno-osobystisnogho stanovlennja majbutnikh fakhivciv: monoghrafija. Donecjk, 2012. 262 s.

6. Kupryjanovskyj V. P., Synjaghov S. A., Lypatov S. Y. y dr. Cyfrovaja эkonomyka - umnыj sposob rabotb. International Journal of Open Information Technologies. 2016. Vol. 4, No. 2. R. 231-238.

7. Kaljjanov A. V., Khljestova O. A. Cyfrova ekonomika v okhoroni praci. Naukovi praci MAUP. Serija «Ekonomichni nauky». Vyp. 2. (58). S. 16-21. URL: https://doi.org/10.32689/2523-4536-2019-02/58-1621. 2019.

8. Shkonda V. V., Kaljjanov A. V. Problemy rozvytku ljudsjkogho potencialu na suchasnomu etapi: monoghrafija. Donecjk: Donbas, 2012. $211 \mathrm{~s}$.

The digitalization of the knowledge economy and the massive transfer of used technologies to a digital basis contributes to an increase in the efficiency of individual enterprises and sectors of the Ukrainian economy. The digitalization of production can provide already in 2025 a significant economic effect and return on investment in a maximum of one year.

The needs of experienced and competent IT industry specialists in the city of Mariupol, Donetsk region and Ukraine have been identified. One of the motivating factors of the needs in their work is decent pay and a wide range of tasks to be solved. However, the profession of IT specialists is associated with excessive mental stress and stress, the possible influence of noise, heat generation, the microclimate of ionizing and non-ionizing radiation, static electricity, insufficient artificial and natural lighting, and visual factors.

Under such conditions, the role and importance of labour protection of IT industry specialist's increases, which should provide a person with safety, comfort and convenience of work. To improve the efficiency of labour protection management, information culture plays an important role as a component of the latest information technologies, which contributes to a conscious attitude of a person to work, the fulfilment of rights and obligations. An expert assessment of the impact of individual components on the development of information culture of IT specialists was carried out, which helps the development and use of valid criteria for assessing information within the framework of the OSH management system. 
Measures have been developed to improve labour protection in the IT industry; prospects for further scientific research on the systemic provision of labour protection in the context of using the latest information technologies in various sectors of the Ukrainian economy have been identified.

ФОРМУВАННЯ ФАКТОРНИХ

СИСТЕМ ЗАБЕЗПЕЧЕННЯ ЕФЕКТИВНОГО

ФУНКЦІОНУВАННЯ МОРСЬКОГО

\section{ПОРТУ}

MAKAPEHKO M. B. доктор економічних наук, професор,

БАРСЬКИИ І. М., аспірант, Донецький державний університет управління
FORMATION OF FACTOR SYSTEMS OF ENSURING EFFECTIVE FUNCTIONING OF THE SEAPORT

Доведено важливість діяльності порту для країни та забезпечення міжнародної торгівлі. Сформовано множину чинників, які визначають рівень ефективності морського порту. Вони були систематизовані щодо вимірювання ефективної діяльності підприємства. Сформовані групи у відповідності до визначення ефективності та отриманих результатів. Підкреслена багатовимірність ефективності морського порту i зростання складності підходів до ії визначення.

Ключові слова: ефективність порту, вимір продуктивності, операційний аспект, просторовий аспект, людський аспект.

Доказана важность деятельности порта для страны и обеспечения международной торговли. Сформулировано множество факторов, которые определяют уровень эффективности морского порта. Они были систематизированы для измерения эффективности работы предприятия. Сформированы группы в соответствии с определением эффективности и результатов. Подчеркивается многомерность эффективности морских портов и возрастающая сложность подходов к ее определению.

Ключевые слова: эффективность порта, измерение производительности, эксплуатационный аспект, пространственный аспект, человеческий аспект.

The importance of the port activities for the country and ensuring international trade is proved. There are many factors that determine the level of efficiency of the seaport. They were systematized to measure the effective operation of the enterprise. Groups according to the definition of efficiency and results are formed. The multidimensionality of seaport efficiency and the increasing complexity of approaches to its definition is emphasized.

Key words: port efficiency, performance measurement, operational aspect, spatial aspect, human aspect. 